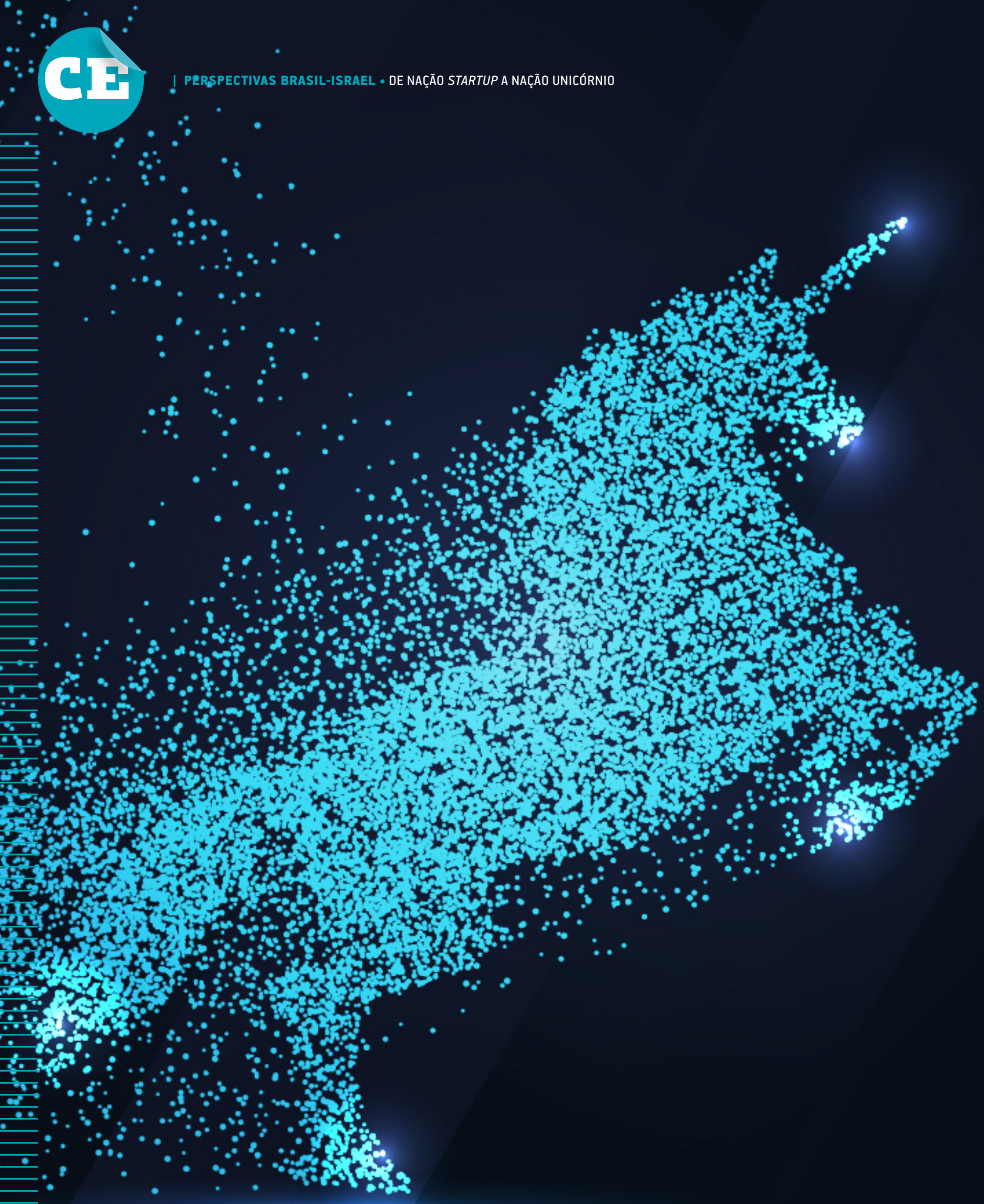




\section{DE NAÇÃO STARTUP A NAÇÃO UNICÓRNIO}

\section{Israel transformou-se de berço de empresas nascentes a cluster de multinacionais tecnológicas com indução do governo, apoio das universidades e interconexão de pessoas e de capital com o mundo.}

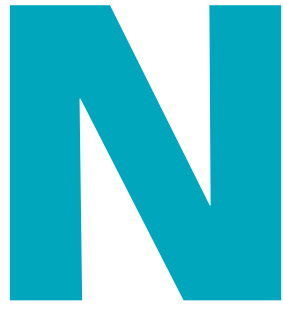

o livro Startup Nation, Dan Senor e Saul Singer buscam explicar por que Israel tornou-se o país com a maior concentração de startups e investimento de capital de risco per capita do mundo. $\mathrm{O}$ argumento central da obra, publicada em 2009, é de que fatores geopolíticos e culturais formam a mola propulsora do fenômeno empreendedor no país. A adversidade geopolítica vinda de terras pouco férteis e a constante ameaça imposta pelos conflitos na região impulsionaram Israel, em suas primeiras décadas, a desenvolver tecnologia na agricultura e na área militar.

A experiência no Exército israelense é analisada como uma grande incubadora de startups. Soldados são absorvidos pela unidade de inteligência do Exército, que criou centenas de soluções tecnológicas posteriormente adaptadas ao contexto civil. Um número expressivo de egressos fundaram empresas de sucesso como a Wix (plataforma de desenvolvimento web), a Palo Alto Networks (plataforma de segurança) e a Check Point (soluções em segurança de tecnologia de informações).
Já a cultura israelense é caracterizada por uma atitude de questionamento e costumes de informalidade e assertividade representados na palavra em hebraico chutzpah (que é um pouco de insolência e um pouco de atrevimento).

Além desses fatores contextuais, os autores de Startup $\mathrm{Na}$ tion destacam que, a partir de 1993, o país começou a superar o ciclo econômico anterior, caracterizado pela agricultura dos kibutzim, comunidades agrícolas em que as propriedades e meios de produção eram coletivos. Com o programa Yozma, o governo israelense impulsionou um ciclo de inovação baseado no desenvolvimento da indústria de capital de risco, o que acabou alavancando a eclosão de startups no país. O governo teve uma postura ativa de fomento da chamada hélice tripla da inovação, caracterizada pela relação entre governo, indústria e universidades.

Apesar do sucesso do ecossistema de inovação israelense no final dos anos 2010, alguns críticos indicavam que grande parte das empresas que cresciam acabavam sendo compradas por grandes firmas estrangeiras. Seria esse um sinal de uma economia insuficientemente forte para servir de âncora para grandes empresas multinacionais? Após 12 anos de lançamento do livro, Israel continua a nação startup? 


\section{INVESTIMENTO EM EMPRESAS DE ALTA TECNOLOGIA EM ISRAEL (EM US\$ BILHÕES)}

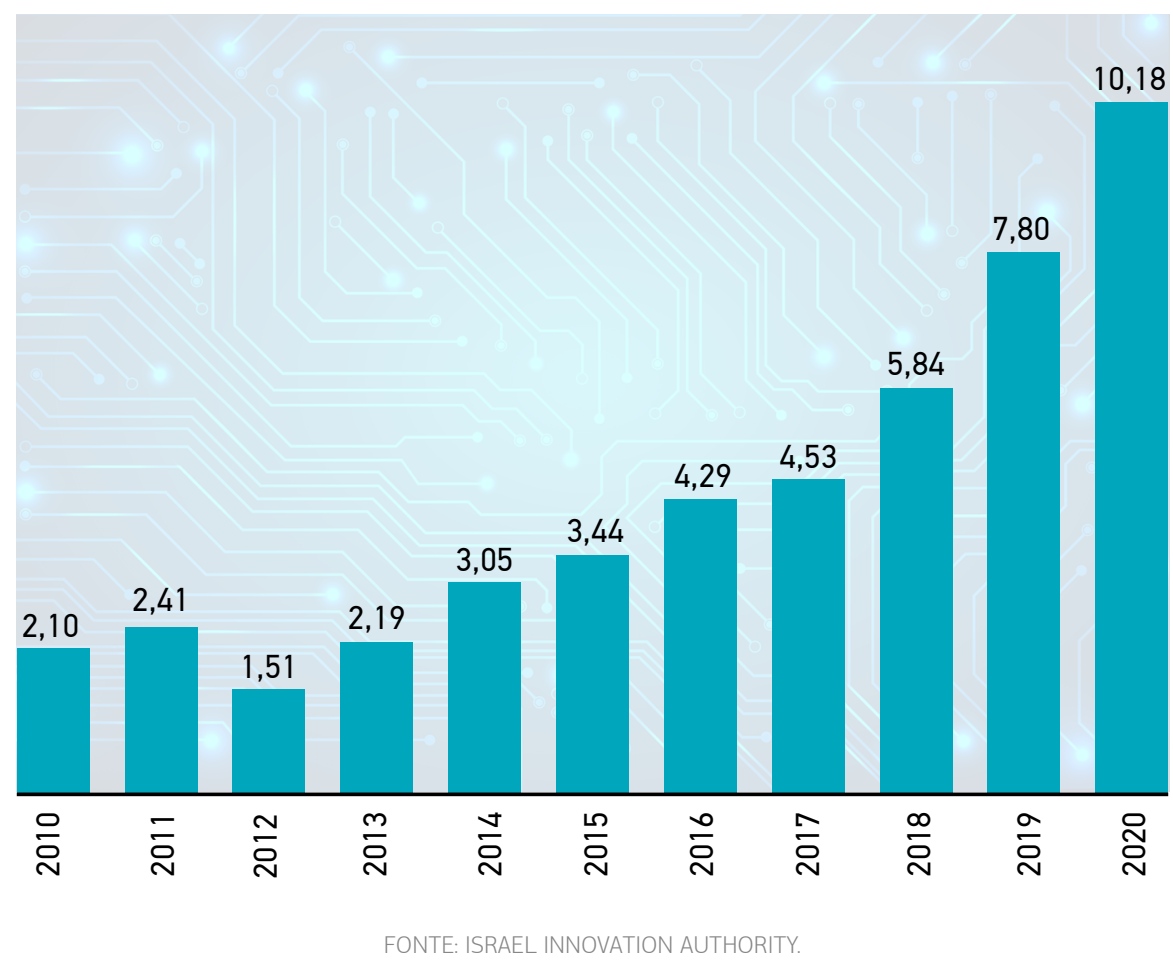

\section{MULTINACIONAIS DE TECNOLOGIA}

Segundo dados da Autoridade de Inovação de Israel, o país tem cerca de 6 mil empresas startups, o que é quase o dobro do número apontado em Startup Nation. A despeito da COVID-19, o investimento em startups do país totalizou 11,5 bilhões de dólares, quatro vezes mais que no fim da década anterior. Grande parte desse crescimento é atribuído à captação de empresas em estágio avançado (late stage), que já são scale ups (empresas de alto crescimento que sustentam o aumento de escala por um longo período). Já a taxa de crescimento de startups e o volume de investimentos dedicado aos estágios iniciais e intermediários do negócio diminuíram consideravelmente desde 2015.

Apesar da pandemia, nada menos que 27 empresas israelenses atingiram o mitológico porte de unicórnios (empresas com valor de mercado avaliado em mais de 1 bilhão de dólares), apenas entre 2020 e agosto de 2021. Se olharmos para os sócios da empresa (em vez da sede), o número de unicórnios nesse período sobe para 48. E outras dezenas de empresas são candidatas a atingirem esse porte nos próximos dois anos. Ainda no mesmo período ocorreu uma eclosão de abertura de capital (IPO - Initial Public Offering ou
Oferta Inicial de Ações) nas bolsas americanas de 18 empresas ( 7 das quais a sede fica em Israel).

O livro Startup Nation indicava que uma das limitações, à época, era que a maior parte das startups israelenses acabavam sendo adquiridas, o que significaria que o país não seria capaz de gerar grandes empresas multinacionais. A evolução do ecossistema de inovação israelense mostra que a fase startup foi superada e, a partir de 2020, Israel teria se tornado a nação unicórnio. Isoladamente, a valoração de uma empresa em 1 bilhão de dólares diz muito pouco, mas, olhando de maneira agregada, os números de Israel demonstram que o país entrou na fase de multinacionais de tecnologia.

Em 2009, os pesquisadores Jerome S. Engel e Itxaso del-Palacio desenvolveram o conceito de cluster global de inovação para descrever a especialização não em indústrias, mas sim em termos de estágio de desenvolvimento e inovação. Sua característica distintiva é aglutinar diversos atores para o rápido crescimento de startups de novas tecnologias capazes de atender o mercado global. O Vale do Silício é visto como arquétipo desse tipo de cluster pela agregação de empreendedores, capital de risco, empresas madu- 
ras, universidades e governo, centros de pesquisa e desenvolvimento e rede de serviços especializados de apoio. De acordo com Engel e del-Palacio, o desenvolvimento acelerado de empresas de tecnologia nesse modelo de cluster é favorecido por mobilidade alta de recursos (capital, pessoas e informação, incluindo propriedade intelectual), velocidade crescente do desenvolvimento de negócios, perspectiva estratégica global e alinhamento cultural entre os atores.

Fora do Vale do Silício, o ecossistema de inovação de Israel se consolida como o grande exemplo contemporâneo desse modelo. Os críticos chamam a atenção para o fato de a maior parte dessas multinacionais estar sediada em Nova Iorque ou no Vale do Silício. Mas isso faz diferença para o país? Diversas razões estratégicas e particulares a cada negócio levam à mudança de sede para os Estados Unidos, mas muitas delas mantêm a maior parte do desenvolvimento tecnológico em Israel, gerando emprego e renda no país.

O maior gargalo do ecossistema de inovação israelense é a falta de mão de obra especializada. Diferentes estimativas indicam uma demanda de algo entre 12 mil e 20 mil vagas. Em 2018, o governo israelense estabeleceu um programa especial de vistos de trabalho para o setor de alta tecnologia, mas essa ação ainda não foi o suficiente para suprir a demanda. Iniciativas como a do Hadassah Academic College, apresentadas nesta edição em artigo de Tali Hadasa Blank, procuram formar segmentos da sociedade israelense sub-representados na indústria de alta tecnologia e podem contribuir para enfrentar o gargalo.

\section{CAMINHOS PARA O BRASIL}

Quais lições a evolução do ecossistema de inovação israelense podem trazer para o Brasil?

O ecossistema de inovação brasileira também passou por grandes mudanças na última década. Houve um crescimento explosivo no número de startups, do investimento de capital de risco e, por fim, de abertura do capital de empresas tanto nos Estados Unidos quanto no Brasil.

Algumas características do desenvolvimento do ecossistema de inovação em Israel ainda oferecem lições que podem ser desenvolvidas no Brasil:

- O governo tem papel importante. A história da nação startup mostra que o governo israelense teve um papel ativo na transformação social e econômica do país. Na nova fase, o governo continua a desempenhar papel estratégico no fomento da inovação e no estabelecimento da infraestrutura institucional para a competitividade. Já no Brasil, salvo iniciativas isoladas de governos municipais e estaduais (e algumas no âmbito federal) que às vezes padecem de continuidade, o empreendedorismo ainda triunfa, apesar do governo, e não por causa do apoio do governo. Infelizmente, governos de esquerda a direita ainda não foram capazes de entender o papel estratégico da inovação no desenvolvimento do país, e o tema de políticas públicas de inovação não tem feito parte da agenda política.

- Instituições educacionais são chaves. As universidades israelenses têm desenvolvido mão de obra e empreendedores para o ecossistema de inovação, mas sua participação na construção da nação startup vai além. As pesquisas de ponta geram recursos por meio da comercialização de patentes, e o ambiente de cooperação científica entre setor privado, governo e universidades é alinhado. A lição é que a pedra fundamental do desenvolvimento se assenta no aumento do nível de educação da população. As universidades também precisam mudar sua relação com o desenvolvimento e comercialização de propriedade intelectual e abrir-se mais à sociedade para cooperar com a iniciativa privada.

- Interconexão global. O desenvolvimento científico e econômico contemporâneo depende de conexões globais que são estabelecidas no âmbito pessoal. A mobilidade de pessoas cria conexões que são elos fundamentais do crescimento acelerado do ecossistema de inovação. A fluidez de capital e de pessoas tem caracterizado o desenvolvimento da inovação em Israel nos últimos anos. Caso marcante desse movimento é a internacionalização da Universidade Technion, que estabeleceu um campus com parceiros locais em Guangdong, China, e outro com a Universidade Cornell, em Nova Iorque. Por outro lado, o Brasil continua sendo um país no qual se é caro e difícil importar e no qual o empreendedor não tem mentalidade global (global mindset) desenvolvida. O fato de o Brasil ser um país gigante não pode mais servir de desculpas para o fomento a uma mentalidade provinciana.

PARA SABER MAIS:

Jerome S. Engel e Itxaso del-Palacio. Global networks of clusters of innovation: accelerating the innovation process. Business Horizons, v.52, n.5, 2009.

Dan Senor e Saul Singer 2009. Start-Up Nation: The Story of Israel's Economic Miracle. New York, NY: Hachette Book Group, 2009.

- Gilberto Sarfati. Quem (e como) investe em startups brasileiras. GV-Executivo, v.17, n.3, maio-jun. 2018.

Gilberto Sarfati. Entrepreneurship and the face of Janus of institutions: stimulus policies for high-impact entrepreneurs in Brazil and Russia. Teoria e Prática em Administração v.9, n.1, 2019.

GILBERTO SARFATI > Professor associado de empreendedorismo e coordenador do Mestrado Profissional em Gestão para Competitividade (MPGC) da FGV EAESP > gilberto.sarfati@fgv.br 